\title{
Antral motility in patients with cirrhosis with or without gastric antral vascular ectasia
}

\author{
J Charneau, R Petit, P Calès, A Dauver, J Boyer
}

\begin{abstract}
Gastric motility has not been extensively studied in patients with cirrhosis and gastric antral vascular ectasia (GAVE) may be associated with antropyloric dysfunction. This study therefore looked at antral motility using ultrasound in patients with alcoholic cirrhosis with or without GAVE. Twenty six patients were included: 10 patients with cirrhosis without GAVE, eight patients with cirrhosis and GAVE, and eight controls without liver disease. Measurement of antral area and antral contractions (amplitude and frequency) was performed for three hours after ingestion of a standardised solidliquid meal. Antral area half time (mean (SD)) was not significantly increased in patients with cirrhosis without GAVE (84 (42) $\mathrm{min}$ ), but increased by $120 \%$ (123 (43) min; $p<0.01$ ) in patients with GAVE compared with controls (56 (26) min). GAVE patients exhibited the same frequency and amplitude of antral contractions at each time point as controls and had the same tendency to increase these values over time although this was attenuated in the late postprandial phase. In contrast, cirrhotic patients without GAVE exhibited a significantly higher frequency and amplitude of antral contractions during the initial postprandial phase but showed no change in either frequency or amplitude over time. In conclusion, in cirrhosis there is an abnormal antral motor response to a meal, which has a different pattern over time in patients with or without GAVE.
\end{abstract}

(Gut 1995; 37: 488-492)

Keywords: antral vascular ectasia, cirrhosis, antral motility.

Department of HepatoGastroenterology

J Charneau

R Petit

$P$ Calès

J Boyer

Department of Radiology, University Hospital, Angers, France

A Dauver

Correspondence to: Dr P Calès, Department of Hepato-Gastroenterology, University Hospital, 49033 Angers Cedex 01, France.

Angers Cedex 01, France. 8 February 1995 in rats with prehepatic portal hypertension. ${ }^{4}$

Gastric antral vascular ectasia (GAVE) is a diffuse mucosal abnormality restricted to the gastric antrum, and is seen in 3\% of patients with cirrhosis. ${ }^{5}$ This disorder was precisely described at endoscopy: red stripes located in the antrum radiating onto the pylorus.

Most cases resemble 'the stripes on a watermelon', ${ }^{6}$ but the appearance can be confluent and diffuse without longitudinal rows. ${ }^{7}$ The histopathological characteristics consist of dilated tortuous mucosal capillaries with focal thrombosis, and fibromuscular hyperplasia. ${ }^{8}$ GAVE has a tendency to bleed and is responsible for severe iron deficiency anaemia. ${ }^{67}$ The pathogenesis is not well known but abnormal antropyloric motility is suspected. ${ }^{6}$

The aims of this study were: (a) to evaluate the antral motility and area in patients with cirrhosis, (b) to compare these abnormalities in patients with cirrhosis with and without GAVE.

\section{Methods}

\section{Patients}

Between January 1993 and July 1993 a total of 26 consecutive patients were included in this study and divided in three groups. The first group included eight patients with alcoholic cirrhosis and GAVE. The second consisted of 10 patients with alcoholic cirrhosis but without GAVE. The diagnosis of cirrhosis was based on liver biopsy or clinical data, or both. An alcoholic aetiology was accepted when alcohol consumption had been greater than $80 \mathrm{~g} /$ day for the past five years and no other cause was evident. Patients with cirrhosis had no ascites. The diagnosis of GAVE was based on gastroscopic appearance, ${ }^{8}$ and diagnosis was confirmed histologically. ${ }^{9}$ Gastroscopic examination was performed within one month before inclusion in the study. None of the patients had overt gastrointestinal bleeding or had had oesophageal variceal sclerotherapy. The third group included eight control patients without chronic liver disease, without GAVE, and with no known history of gastrointestinal disease. The absence of liver disease was defined by normal liver function tests and the absence of a previous history of liver disease. These patients did not drink alcohol to excess. There were two healthy subjects, three patients with choledocholithiasis, one with diverticular disease of the colon, two with depression syndrome. This study was approved by the local medical ethics committee (CCPPRB of Angers) on 10 November 1992, informed written consent was obtained from each patient.

\section{Bioclinical determinations}

Gastrin and serotonin serum concentrations and blood haemoglobin values were determined in all patients after an overnight fast. The Child-Pugh score was determined in patients with cirrhosis. 


\section{Ultrasound study}

Ultrasound examinations were performed with a $5 \mathrm{MHz}$ sound probe (Toshiba) before and $2,15,30,60,90,120,150 \mathrm{~min}$ after a standard solid-liquid meal containing 2000 kcal consisting of $20 \%$ protein, $55 \%$ carbohydrate, and $25 \%$ lipid ( 2 eggs, $50 \mathrm{~g}$ of beef liver, 1 cup of coffee with $5 \mathrm{~g}$ of sugar, $150 \mathrm{ml}$ of orange juice, 2 slices of toast and $20 \mathrm{~g}$ of butter). None of the patients had received drugs that affected gastrointestinal motility, alcohol or tobacco for 48 hours before and during the examination. The meal was ingested in less than 10 minutes by all patients. All the patients were examined in the upright position while the probe was positioned vertically to simultaneously visualise the antrum, the superior mesenteric vein, and the aorta. These vessels served as landmarks to standardise the position of the scan. This scan was used to identify the antral area, the frequency and amplitude of antral contractions. The scan was recorded on a videotape for two minutes at the above mentioned periods, except at two minutes. All examinations and measurements were performed by one investigator who was unaware of the group.

\section{Antral area}

The antral area was calculated by measuring the longitudinal $(\mathrm{L})$ and anteroposterior (P) diameters of the antral area, and using the formula $\pi \mathrm{L} . \mathrm{P} / 4 .^{10}$ The measurements were performed between two antral contractions, and during expiration while the patients stopped breathing. Besides absolute values and to avoid individual variability of the basal gastric antrum size, modifications of the antral area induced by the standard meal were calculated in terms of antral area ratios (ratios between the area at fixed time intervals and the basal value) and then transferred to a curve as a function of time. This ratio represents the degree of dilatation of the gastric antrum at each of the above mentioned periods, except at two minutes. In this ratio, the basal value was calculated by subtracting the antral area measurement before the meal to the antral area measurement at two minutes after the meal using a method described elsewhere. ${ }^{11}$ This corresponded to $100 \%$ of the retained meal. Thus the antral area ratio at time $\mathrm{X}$ was calculated according to the formula: $(\mathrm{Sx}-\mathrm{So}) /(\mathrm{S} 2-\mathrm{So})$ where So, S2, Sx are antral area respectively at time 0,2 , and $\mathrm{X}$ minutes. Antral area half time was calculated as the time when the degree of dilatation of the antral area corresponded to half the basal value.

Clinical and biochemical data

\begin{tabular}{lrllllll}
\hline & $N o$ & $\begin{array}{l}\text { Sex } \\
M / F\end{array}$ & $\begin{array}{l}\text { Age } \\
(y)\end{array}$ & $\begin{array}{l}\text { Child-Pugh } \\
\text { score }\end{array}$ & $\begin{array}{l}\text { Gastrin } \\
(n g / m l)\end{array}$ & $\begin{array}{l}\text { Serotonin } \\
(\text { ng/ml) }\end{array}$ & $\begin{array}{l}\text { Haemoglobin } \\
(\text { dg/l) }\end{array}$ \\
\hline Control & 8 & $4 / 4$ & $54(19)$ & NA & $53(17)$ & $65(36)$ & $14 \cdot 1(1 \cdot 2)$ \\
Cirrhosis & 10 & $8 / 2$ & $49(12)$ & $7 \cdot 4(1 \cdot 5)$ & $48(21)$ & $56(32)$ & $11 \cdot 8(3 \cdot 0)$ \\
GAVE & 8 & $8 / 0$ & $67(6)$ & $7 \cdot 9(1 \cdot 9)$ & $127(196)$ & $196 \cdot 5(335)$ & $10 \cdot 0(2 \cdot 1)$ \\
p Value & & NS & $<0.05^{\star}$ & NS & NS & NS & $<0.05 \dagger$ \\
\hline
\end{tabular}

GAVE: cirrhotic patients with gastric antral vascular ectasia. ${ }^{\star}$ Cirrhosis $v$ GAVE (pair wise post hoc comparison). †GAVE $v$ controls (pair wise post hoc comparison).

Data shown as mean (SD). NA=not applicable.
Anterior antral wall thickness

Measurements were taken during evaluation of the antral area before the meal. The anterior antral wall was identified by a thin hypoechoic outer layer corresponding to the muscle coat, bounded by a peripheral echogenic layer corresponding to the serosa.

\section{Antral contractions}

The frequency of the antral contractions was defined as the number of contractions during a two minute interval recorded after the meal. The amplitude of the antral contractions was measured when the reduction of the antral area was maximal. It was expressed by $\Delta \mathrm{A} / \mathrm{A}$ where $\Delta \mathrm{A}=$ the difference between the value of the relaxed and contracted area, and $A$ the value of relaxed area.

\section{Statistical analysis}

All quantitative variables were expressed as mean (SD) values (unless otherwise specified). The means were compared with one way analysis of variance followed by pair wise post hoc comparisons. In the case of significant heterogeneity of variance, a Kruskall-Wallis test was used. These tests were used for comparison of clinical and biochemical data, and ultrasound results. The paired $t$ test was used to compare the ultrasound results at 15 minutes and other times in each group. Correlation was tested using Spearman's test. A p value $<0.05$ was considered significant.

\section{Results}

\section{Clinical and biochemical data}

Age in GAVE patients was higher than in patients with cirrhosis without GAVE (Table). There was no significant difference between the three groups for serotonin or gastrin serum concentrations. As expected, blood haemoglobin values were significantly decreased in patients with cirrhosis with GAVE (Table).

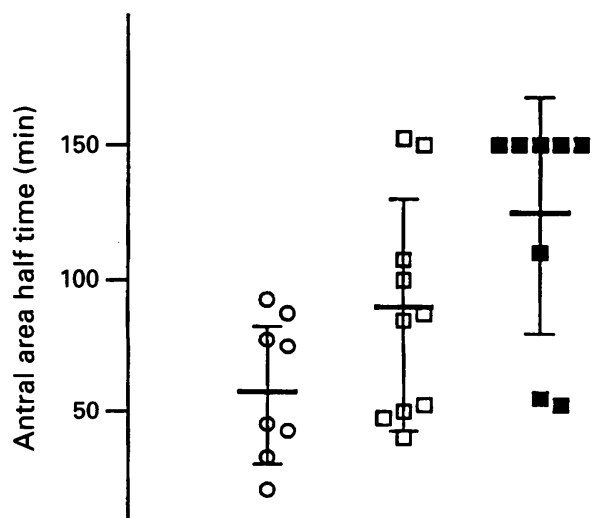

Controls Cirrhosis GAVE

Figure 1: Distribution of single values of the antral area half time in controls, cirrhotic patients, and GAVE patients. Vertical bars denote mean (SD). 


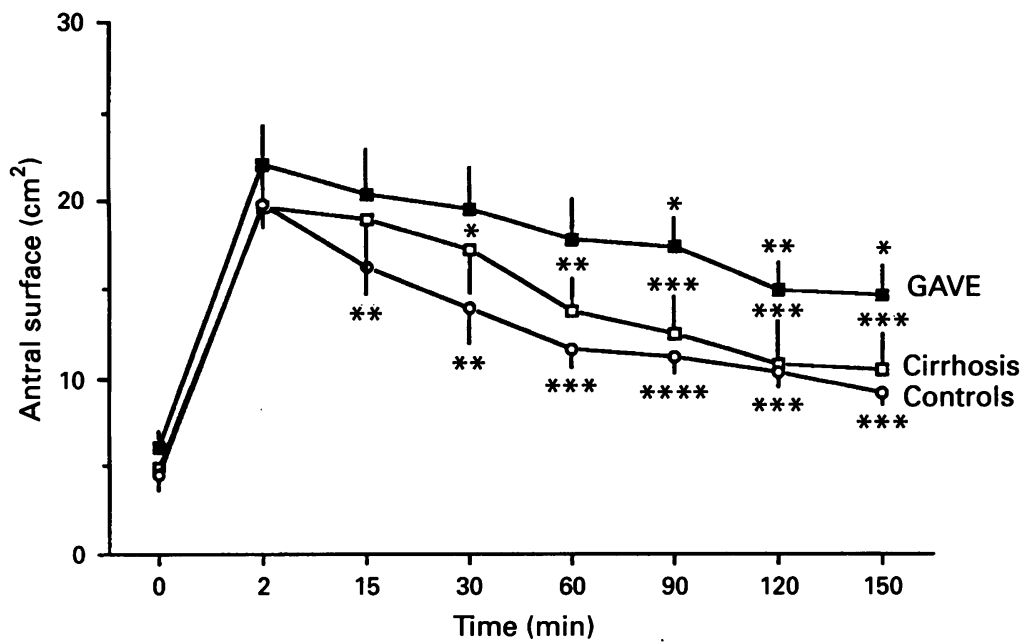

Figure 2: Antral area as a function of time in the three groups. Data are plotted as mean absolute values, the vertical bars represent the SEM. There was no significant differences between the three groups. Asterisks denote significant difference within each group, the reference being two minutes: ${ }^{\star} p<0.05,{ }^{\star \star} p<0.01,{ }^{\star \star \star} p<0.001,{ }^{\star \star \star \star} p<0.0001$.

\section{Ultrasound determination data}

Antral area half time was not significantly increased (86 (42) $\mathrm{min}$ ) in patients with cirrhosis without GAVE, and significantly increased by $120 \%(123$ (43) $\mathrm{min} ; \mathrm{p}<0.01)$ in GAVE patients compared with control subjects (56 (26) min) (Fig 1).

The antral area, and the amplitude and frequencies of antral contractions as a function of time in the three groups are shown in Figs 2, 3,4 , and 5 respectively. Comparisons were made between the three groups at each time point and within each group as a function of time (the time of reference was 15 minutes unless otherwise specified). These results can be summarised as follows.

The reduction in antral area was significantly less during the whole study period (since the motor response was delayed) in GAVE patients compared with other patients (Figs 2 and 3). The results of antral area expressed as absolute values (Fig 2) or ratios (Fig 3) were similar.

There was no significant variation in the frequency of antral contractions in patients with cirrhosis whereas they were significantly more frequent in controls in the second 90 minute phase. Moreover the frequency of

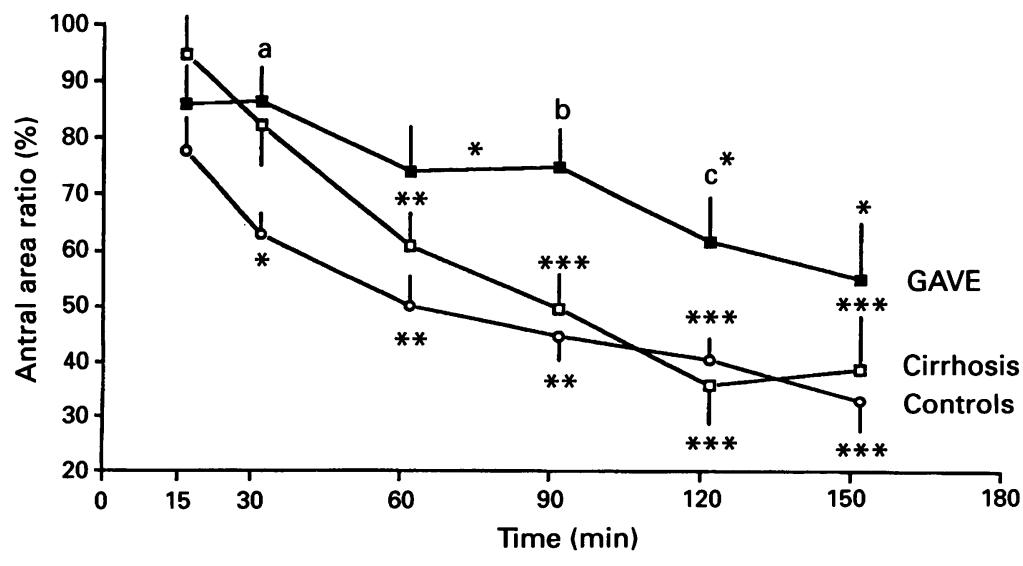

Figure 3: Dilatation of gastric antrum from gastric antral area ratio as a function of time in the three groups. Data are plotted as mean percentage, the vertical bars represent the SEM. Letters denote significant differences between groups. ${ }^{a} p<0.05 \mathrm{v}$ control subjects; ${ }^{\mathrm{b}} p<0.05 \mathrm{v}$ control subjects and cirrhotic patients; ${ }^{c} p<0.05 \mathrm{v}$ cirrhotic patients. Asterisks denote significant difference within each group, the reference being 15 minutes: ${ }^{\star} p<0 \cdot 05$, $\star \star p<0.01, \star \star \star p<0.001$. antral contractions was only significantly increased in the first half hour in patients with cirrhosis without GAVE compared with controls (Fig 4).

The amplitudes of antral contractions were fairly stable as a function of time with only a weakly significant and late increase in GAVE patients (Fig 5). Amplitudes were higher in patients with cirrhosis without GAVE but this was only significant at 30 minutes.

For the whole group of patients, there were no correlations between age or blood haemoglobin value on the one hand and antral area half time or contractions parameters at any time point on the other hand.

In GAVE patients, antral wall thickness $(4 \cdot 3$ (1.9) $\mathrm{mm}$ ) was not significantly increased compared with controls $(3.3(0.5) \mathrm{mm})$ or with patients with cirrhosis without GAVE (3.9 (1) $\mathrm{mm}$ ).

\section{Discussion}

To our knowledge, this is the first study that evaluates antral motility in patients with cirrhosis with or without GAVE. Ultrasound is considered an easy, safe, and non-invasive technique to quantify gastric emptying, by measuring the cross sectional area of the gastric antrum. ${ }^{10-13}$ The validity of this method was confirmed in healthy subjects by comparison with scintigraphy, which represents the gold standard method. ${ }^{10}$ The correlation with scintigraphy also seems to be greater for the liquid phase emptying of the gastric content than for the solid one. ${ }^{11}$ Other authors have studied antroduodenal motility using ultrasound ${ }^{14-16}$ and the proximal duodenal in a single plan.

However, there are certain problems with ultrasound. It is time consuming, subcutaneous fat and bowel gas may change the picture, and patients must stay in an upright position to use the 'acoustic window' of the descending left lobe of the liver, and to displace the interposed intestinal loops. As a solid-liquid meal was used, it was difficult to visualise the antrum, pyloric channel, and the proximal duodenum in a single section. Consequently, coordinated antroduodenal contractions and transpyloric fluid movements were not evaluated.

Patients with cirrhosis and GAVE were older, which probably results from the natural history as this condition is found in older patients with cirrhosis. ${ }^{17}$ The lack of correlation between motility variables and age should be emphasised when interpretating results. The results of antral motility in the controls in this study, were similar to those reported in healthy subjects by Houghton et al. ${ }^{18}$ These authors have shown a higher frequency of coordinated antroduodenal events during the second postprandial hour compared with the first postprandial hour after ingestion of $300 \mathrm{ml}$ of milk. In our study, GAVE patients exhibited the same postprandial pattern of antral contraction frequencies and amplitudes as controls. Moreover, antral area was significantly higher in GAVE patients than in 


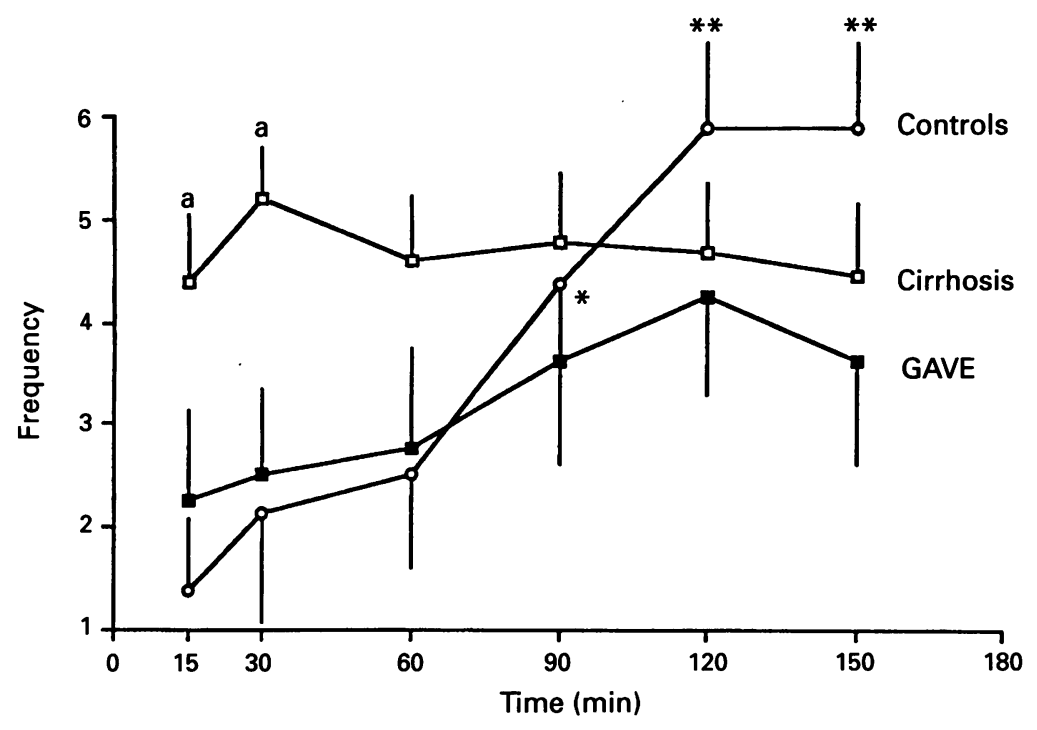

Figure 4: Frequency (no/2 min) curves of antral contractions in relation to time in the three groups. Data are plotted as mean, the vertical bars represent the SEM. Letters denote significant differences between groups. a $p<0.05 \mathrm{v}$ control subjects. Asterisks denote significant difference within each group, the reference being 15 minutes: ${ }^{\star} p<0.05$, ${ }^{\star \star} p<0.01$.

controls. Therefore, isolated pyloric pressure waves might have reduced gastric emptying by intermittently obstructing flow through the pylorus.

In contrast, the patients with cirrhosis without GAVE showed a different pattern characterised by a significantly higher frequency and amplitude of antral contractions from the earliest postprandial phase but no change in either frequency or amplitude throughout the period of study. Moreover, the level of antral dilatation was similar to controls. In these patients an uncoordinated antropyloroduodenal activity with a decreased transpyloric flow might have occurred.

Three teams have studied gastric motility and emptying in patients with cirrhosis. Using a scintigraphic method, Suyama et $a l^{2}$ and Isobe et al ${ }^{19}$ have shown that gastric emptying half time was significantly higher in patients with cirrhosis than in controls. Mansurov and Pisanova ${ }^{1}$ found that patients with cirrhosis presented hypokinetic electrogastrograms after stimulation of the gastric wall compared with healthy subjects. Chesta $e t a^{3}$ did not find significantly changed gastric emptying after a solid meal in patients with cirrhosis compared



Figure 5: Amplitude curves of antral contractions in relation to time in the three groups. Data are plotted as mean, the vertical bars represent the SEM. Letters denote significant differences between groups. ${ }^{a} p<0.05 \mathrm{v}$ control subjects or $G A V E$ patients. Asterisks denote significant difference within each group, the reference being 15 minutes: ${ }^{\star} p<0.05$. with healthy controls. Also the presence of GAVE was not mentioned in these studies. The cause of this dysfunction is uncertain. Vagal nerve increases and regulates antroduodenal motility by the release of acethylcholine. Thus, denervation of the digestive autonomic nervous system may occur and cause a loss of propulsive and coordinate activity. Pyloric tone is almost entirely dependent on the sympathetic nervous system. In chronic liver disease patients, an autonomic cardiovascular neuropathy has been described and was associated with a significantly worse follow up, independent of hepatic damage. ${ }^{20}$ This neuropathy was not alcoholic related because it was as common in patients with alcohol related liver disease as those without. Moreover gastric emptying was not changed in alcoholic patients without cirrhosis compared with healthy controls. ${ }^{21}$ Therefore autonomic neuropathy might result from ultrastructural or biochemical changes in smooth muscular or enteric nerves. Vasoactive intestinal peptide receptors and opiate receptors are found in the normal pyloric area. Naloxone can inhibit pyloric pressure waves induced by duodenal acidification, ${ }^{22}$ and has also been shown to inhibit delayed gastric emptying induced by a kappa opiate receptor agonist in the $\operatorname{dog} .{ }^{23}$ The increase in the endogenous opioid peptides described in cirrhosis ${ }^{24}$ could contribute to antral motor abnormalities. Moreover, if changed antropyloric motility is confirmed in patients with cirrhosis, naloxone analogues may represent a new therapeutic modality for this dysfunction.

The pathogenesis of GAVE is poorly known. It has been suggested that GAVE may represent an antral lesion acquired from repeated antral mucosal trauma, like in pyloric prolapse syndrome. ${ }^{6}$ Suit et al noted that fibromuscular hyperplasia resembled gastrointestinal lesions acquired from repeated mucosal trauma in stomas and areas of intussusception such as rectal prolapse syndrome. ${ }^{25}$ Our study supports this hypothesis.

Moreover, the endoscopic characteristics such as longitudinal antral folds converging on the pylorus seen in the watermelon stomach also support this hypothesis. ${ }^{67}$ Jabarri et al showed that the muscular layer in the pyloric region was thickened on a cross section of an antral specimen. Our study showed, however, that antral wall thickness was not significantly increased in GAVE patients compared with other groups. There was a tendency towards increase, however, so the lack of difference might result from a type II error.

Other mechanisms such as changed enteric hormones and peptides may also be involved. Quintero et $a l^{5}$ have found that gastrin serum concentrations were significantly increased in patients with cirrhosis and GAVE. Gostout et $a l^{7}$ saw that serum gastrin was increased in $76 \%$ of patients with GAVE. Gastrin increases both the contractility of the antrum and pyloric and duodenal contractility and pressure, this resulting in impeded emptying. ${ }^{26}$ Lowes and Rode $^{27}$ reported a case of watermelon stomach in a patient whose resected stomach showed 
chronic atrophic gastritis with intraepithelial neuroendocrine proliferations containing large quantities of 5-hydroxytryptamine and vasoactive intestinal polypeptide. They suggested that vasodilatation may be a consequence of mediators released from proliferated neuroendocrine cells. In our study, gastrin and serotonin serum concentrations were not significantly increased in GAVE patients compared with other groups. The apparent increase in GAVE patients (serotonin: $\times 3 \cdot 5$, gastrin: $\times 2 \cdot 6$ ) resulted from a few patients, thus a type II error cannot be completely ruled out.

We are indebted to Professor Arhan for his suggestions. This study was supported by the $\mathrm{C} \mathrm{H}$ U d'Angers.

1 Mansorov KK, Pisanova AA. Acid-forming and motor function of the stomach in patients with chronic hepatitis and liver cirrhosis. Sov Med 1977; 12: 27-30.

2 Suyama $H$. Studies on gastric emptying time in patients with liver cirrhosis by radioisotope techniques. Nippon Shokakibyo Gakkai Zasshi 1984; 81: 2507-15.

3 Chesta J, Lillo R, Defilippi C, Velasco M, Katz R. Orocecal transit time and gastric emptying in patients with cirrhosis. Gastroenterology 1991; 100: A43.

4 Reilly JA, Forst CF, Quigley EMM, Rikkers LF. Gastric emptying of liquids and solids in the portal hypertensive rat. Dig Dis Sci 1990; 35: 781-6.

5 Van Vliet ACM, Ten Kate FJW, Dees J, Van Blankenstein $M$. Abnormal blood vessels of the prepyloric antrum in cirrhosis of the liver as a cause of chronic gastrointestinal cirrhosis of the liver as a cause of ch

6 Jabbari M, Cherry R, Lough JO, Daly DS, Kinnear DG, Goreski CA. Gastric antral vascular ectasia: the watermelon stomach. Gastroenterology 1984; 87: 1165-70.

7 Lee FI, Costello F, Flanagan N, Vasudev KS. Diffuse antral vascular ectasia. Gastrointest Endosc 1984; 30: 87-90.

8 Payen JL, Calès $P$, Voigt JJ, Barbe $S$, Pilette $C$, Dubuisson $\mathrm{L}$, et al. Severe portal hypertensive gastropathy and antral vascular ectasia are distinct entities in patients with cirrhosis. Gastroenterology 1995; 108: 138-44.

9 Gilliam JH, Geisinger KR, Wu WC, Weidner N, Richter JE. Endoscopic biopsy is diagnostic in gastric antral vascular Endoscopic biopsy is diagnostic in gast

10 Bolondi L, Bortolotti M, Santi V, Calletti T, Gaiani S, Labo G. Measurement of gastric emptying time by real-time ultrasonography. Gastroenterology 1985; 89: 752-9.
11 Dapoigny $\mathbf{M}$, Bonnafous J, Della Salle $\mathbf{P}$, Abergel A Pelissier E, Veyre A, et al. Validation d'une méthode échographique de mesure de la vidange gastrique chez 'homme. Gastroenterol Clin Biol 1991; 3: 199-203.

12 Bateman DN, Whittingham TA. Measurement of gastric emptying by real time ultrasound. Gut 1982; 23: 524-7.

13 Holt S, Cervantes J, Wilkinson AA, Wallace JHK Measurement of gastric emptying rate in humans by realtime ultrasound. Gastroenterology 1986; 90: 918-23.

14 Holt S, McDicken WN, Andeson T, Stewart IC, Heading RC. Dynamic imaging of the stomach by real-time ultrasound: a method for the study of gastric motility. Gut 1980; 21: 597-601.

15 Hausken T, Deggard S, Berstad A. Antroduodenal motility studied by real time ultrasonography. Effect of enprostil. Gastroenterology 1991;100: 59-63.

16 King PM, Adam RD, Pryde A, McDicken WN, Headin RC. Relationships of human antroduodenal motility and ranspyloric fluid movement: non-invasive observation with real-time ultrasound. Gut 1984; 25: 1384-91.

17 Calès P, Payen JL, Berg P, Voigt JJ, Desmorat H, Vinel JP et al. Antral vasular ectasia: new endoscopic and clinical spectrum. Gastroenterology 1991; 100: A38.

18 Houghton LA, Read NW, Heddle R, Maddern GJ, Downton J, Tooli J, et al. Motor activity of the gastric antrum, pylorus, and duodenum under fasted conditions antrum, pylorus, and duodenum under fasted conditions

19 Isobe H, Sakai H, Satoh M, Sakamoto S, Nawata H. Delayed gastric emptying in patients with liver cirrhosis Dig Dis Sci 1994; 39: 983-7.

20 Hendrickse MT, Thuluvath PJ, Triger DR. Natural history of autonomic neuropathy in chronic liver disease. Lance 1992; 339: 1462-4

21 Wegner M, Schaffstein J, Dilger U, Coenen DC, Weldmann B, Schmidt G. Gastrointestinal transit of solid-liquid meal in chronic alcoholics. Dig Dis Sci 1991; 36: 917-23.

22 Dooley CP, Reznick JB, Valenzuela JE. A continuous manometric study of the human pylorus. Gastroenterolog 1985; 89: 821-6.

23 Gué M, Fioramonti J, Honde C, Pascaud X, Junien JL Bueno L. Opposite effects of K-opioid agonists on gastric emptying of liquids and solids in dogs. Gastroenterolog 1988; 95: 927-31.

24 Thornton JR, Dean H, Losowsky MS. Is ascites caused by impaired hepatic inactivation of blood-borne endogenous opioid peptides? Gut 1988; 29: 1167-72.

25 Suit PF, Petras RE, Bauer TW, Petrini JL Jr. Gastric antral vascular ectasia: a histologic and morphometric study of the watermelon stomach. Am 7 Surg Pathol 1987; 11: $750-7$.

26 Valenzuela JE, Grossman MI. Effects of pentagastrin and caerulein on intragastric pressure in dogs. Gastroenterology caerulein on intragast

27 Lowes JR, Rode J. Neuroendocrine cell proliferations in gastric antral vascular ectasia. Gastroenterology 1989; 97 207-12. 